Article

\title{
Investigation of Recessed Gate AlGaN/GaN MIS-HEMTs with Double AlGaN Barrier Designs toward an Enhancement-Mode Characteristic
}

\author{
Tian-Li Wu *, Shun-Wei Tang and Hong-Jia Jiang \\ International College of Semiconductor Technology, National Chiao Tung University, Hsinchu 30010, Taiwan; \\ tangandy.icst07g@nctu.edu.tw (S.-W.T.); dk0754013.icst07g@nctu.edu.tw (H.-.J.J.) \\ * Correspondence: tlwu@nctu.edu.tw; Tel.: +886-3-571212
}

Received: 31 December 2019; Accepted: 2 February 2020; Published: 3 February 2020

check for updates

\begin{abstract}
In this work, recessed gate $\mathrm{AlGaN} / \mathrm{GaN}$ metal-insulator-semiconductor high-electronmobility transistors (MIS-HEMTs) with double AlGaN barrier designs are fabricated and investigated. Two different recessed depths are designed, leading to a $5 \mathrm{~nm}$ and a $3 \mathrm{~nm}$ remaining bottom AlGaN barrier under the gate region, and two different $\mathrm{Al} \%(15 \%$ and $20 \%)$ in the bottom $\mathrm{AlGaN}$ barriers are designed. First of all, a double hump trans-conductance $\left(g_{\mathrm{m}}\right)$-gate voltage $\left(V_{\mathrm{G}}\right)$ characteristic is observed in a recessed gate $\mathrm{AlGaN} / \mathrm{GaN}$ MIS-HEMT with a $5 \mathrm{~nm}$ remaining bottom $\mathrm{Al}_{0.2} \mathrm{Ga}_{0.8} \mathrm{~N}$ barrier under the gate region. Secondly, a physical model is proposed to explain this double channel characteristic by means of a formation of a top channel below the gate dielectric under a positive $V_{\mathrm{G}}$. Finally, the impacts of $\mathrm{Al} \%$ content (15\% and $20 \%$ ) in the bottom AlGaN barrier and $5 \mathrm{~nm} / 3 \mathrm{~nm}$ remaining bottom $\mathrm{AlGaN}$ barriers under the gate region are studied in detail, indicating that lowering $\mathrm{Al} \%$ content in the bottom can increase the threshold voltage $\left(V_{\mathrm{TH}}\right)$ toward an enhancement-mode characteristic.
\end{abstract}

Keywords: GaN; metal-insulator-semiconductor high-electron-mobility transistor (MIS-HEMT); recessed gate; double barrier

\section{Introduction}

AlGaN/GaN high-electron-mobility transistors (HEMTs) are promising for power switching applications due to the wide band gap, large breakdown electric field, and the inherent high electron mobility due to two-dimensional electron gas (2DEG) [1,2]. Normally, conventional AlGaN/GaN Schottky HEMTs suffer high gate leakage, resulting in an unfavorable power loss during an off-state condition and a low gate overdrive during an on-state condition. In order to tackle this issue, Metal-insulator-semiconductors high electrons mobility transistors (MIS-HEMTs) have gained attentions recently [2-4]. Inserting a dielectric in the interface between AlGaN and gate metal significantly reduces the gate leakage current, allowing a high gate overdrive to have a fast switch from off-state to on-state operation. Due to a piezoelectric and polarization effects, a two dimensional electron gas (2DEG) is naturally formed in the interface between $\mathrm{GaN}$ and AlGaN, leading to depletion mode $\left(V_{\mathrm{TH}}<0\right)$ characteristics. However, an enhancement mode characteristic is more favorable in practical applications due to a lower power consumption, less failure issues, and a flexible integration. So far, there are several approaches to realize an enhancement mode operation, such as a recessed gate structure [5-7], p-GaN/p-AlGaN gate [2,8], Fluoride-based plasma treatment [9], the metal-oxide-semiconductor field-effect transistor structure [10], cascode-based topology in connecting high voltage D-mode HEMTs with a low voltage Si MOSFETs or E-mode HEMTs [11,12], etc. HEMTs with a p-GaN/p-AlGaN gate generally suffer the challenges to effectively 
dope the $\mathrm{Mg}$ into top $\mathrm{GaN}$ or AlGaN layer and to remove the top p-GaN/p-AlGaN layer in the access region. The thermal stability of the charges induced by Fluoride-based plasma remains a challenge. The MOS-type GaN FETs suffer the low electron mobility due to the disappearance of the 2DEG. The cascode-based topology with dual GaN-based transistors increase the active area and complicates the layout designs. Therefore, the recessed gate-based HEMT is one of the most popular architectures to obtaining an enhancement-mode characteristic because the 2DEG can be reduced under the gate by using a simple etching process, i.e., Reactive-ion etching (RIE)-based etching or atomic layer etching (ALE). Recently, the recessed gate $\mathrm{AlGaN} / \mathrm{GaN}$-based devices show a promising performance toward an enhancement-mode characteristic [5-7].

Typically, AlGaN/GaN-based HEMTs are fabricated with the single AlGaN barrier layer. A multi barrier device was demonstrated first in GaAs-based devices in 1985 [13]. Since 1999, a depletion mode double AlGaN barrier design was first demonstrated by Gaska et al. [14]. Afterwards, depletion-mode double AlGaN barrier HEMTs have been explored in details in [15-18], showing a high current drive due to a second transconductance (gm) and lower access resistance. Furthermore, the recent demonstration using AlGaN/AlN/GaN/AlN epitaxy stack to achieve the double channel has attracted a lot of attentions [19]. Although the demonstration of the GaN-based HEMTs with a double barrier exhibits the promising characteristics, the impacts of the $\mathrm{Al} \%$ in the top and bottom $\mathrm{AlGaN}$ barriers are still unclear. Furthermore, the investigation of the combination of the recessed-based approach in the HEMTs with double AlGaN barrier designs is lacking as well, which can further provide the insightful analysis to understand the device physics and structure designs toward an enhancement-mode characteristic.

In this work, recessed gate MIS-HEMTs with double AlGaN barrier designs with different recessed depths ( $3 \mathrm{~nm}$ or $5 \mathrm{~nm}$ remaining bottom $\mathrm{AlGaN}$ barrier under the gate region) and different $\mathrm{Al} \%$ content in the bottom AlGaN barrier (15\% and 20\%) are fabricated and investigated. First of all, we observed a double hump $g_{\mathrm{m}}-V_{\mathrm{G}}$ characteristic in a recessed gate AlGaN/GaN MIS-HEMT with a $5 \mathrm{~nm}$ remaining bottom $\mathrm{Al}_{0.2} \mathrm{Ga}_{0.8} \mathrm{~N}$ barrier under the gate region. Then, a physical model considering the formation of the top channel under a positive $V_{\mathrm{G}}$ is proposed to explain this double hump in the $g_{\mathrm{m}}-V_{\mathrm{G}}$ characteristic. Furthermore, the impacts from the $\mathrm{Al} \%(20 \%$ and $15 \%)$ in bottom AlGaN barrier and recessed depth ( $3 \mathrm{~nm}$ and $5 \mathrm{~nm}$ remaining bottom $\mathrm{AlGaN}$ barrier under the gate region) are discussed to understand the device characteristics and the $\mathrm{V}_{\mathrm{TH}}$ can be increased by designing the device with a lower $\mathrm{Al} \%$ in the bottom $\mathrm{AlGaN}$ barrier.

\section{Device Fabrications}

Figure 1 shows the schematic of the epitaxy structure in this study and Figure 2 shows an example of the transmission electron microscopy (TEM) image in an epitaxy structure with a double AlGaN barrier. This structure was grown by metal-organic chemical vapor deposition (MOCVD) on a silicon (111) substrate and consists of an AlN nucleation layer, a GaN channel, a bottom AlGaN barrier with two different $\mathrm{Al}$ contents ( $20 \%$ and $15 \%$ ), a top $\mathrm{AlGaN}$ barrier with $30 \% \mathrm{Al}$ content, and a $1 \mathrm{~nm} \mathrm{GaN} \mathrm{cap}$. The $\mathrm{Al} \%(20 \%$ and $30 \%)$ in AlGaN barrier is calibrated with the XPS by using a single AlGaN barrier hetero-structure. The calibrated growing conditions in MOCVD are used for the double AlGaN barrier hetero-structure. Figure 3 shows the simulated band diagram with the double AlGaN barriers, clearly indicating the existence of the electrons in the interface between top AlGaN/bottom AlGaN and bottom $\mathrm{AlGaN} / \mathrm{GaN}$. The recessed gate structure was formed by reactive ion etching (RIE). In order to control the etching depth, low etching rate of $5 \AA / \mathrm{sec}$ is achieved by the mixed $\mathrm{BCl}_{3}(10 \mathrm{sccm}) / \mathrm{Cl}_{2}(15 \mathrm{sccm})$ gas. A gate recessed process is performed and a 15-nm Plasma-enhanced chemical vapor deposition (PECVD) $\mathrm{Si}_{3} \mathrm{~N}_{4}$ is deposited as a surface passivation layer in the access region and a gate dielectric. TiN is used as the gate metal. The Ti/Al-based Au-free Ohmic contacts were formed by etching the $\mathrm{Si}_{3} \mathrm{~N}_{4}$ layers and etching the $\mathrm{AlGaN}$ barrier. This was followed by annealing at $600{ }^{\circ} \mathrm{C}$ for $1 \mathrm{~min}$ in $\mathrm{N}_{2}$, resulting in $1 \mathrm{ohm} . \mathrm{mm}$ of $\mathrm{R}_{\mathrm{c}}$ (contact resistance). Figure 4 shows the schematic of recessed gate 
MIS-HEMTs with a double AlGaN barrier. The important varied parameters are summarized in Table 1. The devices with $L g=1 \mathrm{um}, L g s=2 \mathrm{um}$, and $L g d=6 \mathrm{um}$ are fabricated for electrical characterizations.

\begin{tabular}{|c|}
\hline GaN Cap \\
\hline Top $\mathrm{Al}_{0.3} \mathrm{Ga}_{0.7} \mathrm{~N}$ barrier \\
\hline Bottom AIGaN barrier (20\%Al or I5\%Al) \\
\hline GaN Channel \\
\hline AlN \\
\hline Silicon (111) \\
\hline
\end{tabular}

Figure 1. Schematic of the epitaxy structure with a double AlGaN barrier used in this study.

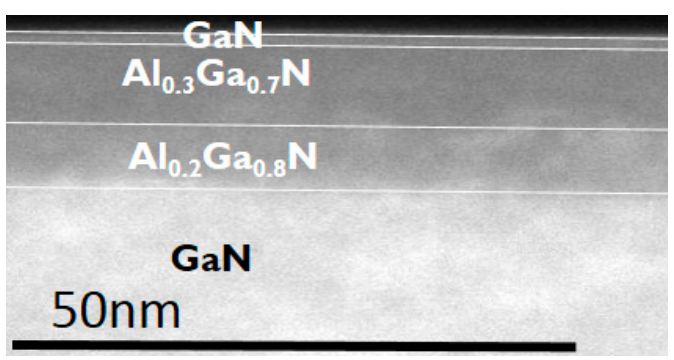

Figure 2. Transmission electron microscopy (TEM) images of the epitaxy structure with a double AlGaN barrier.

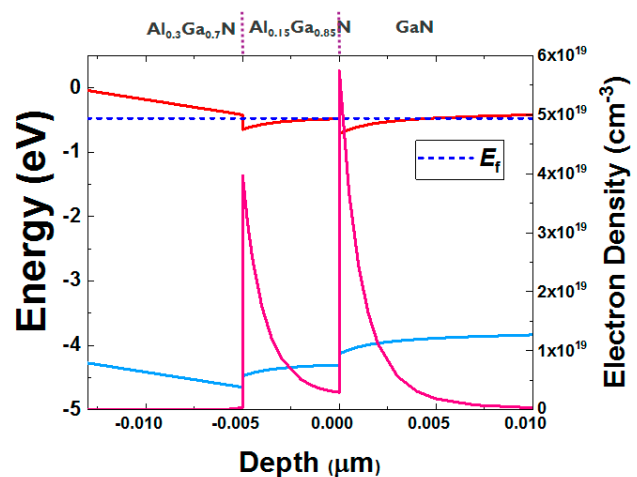

(a)

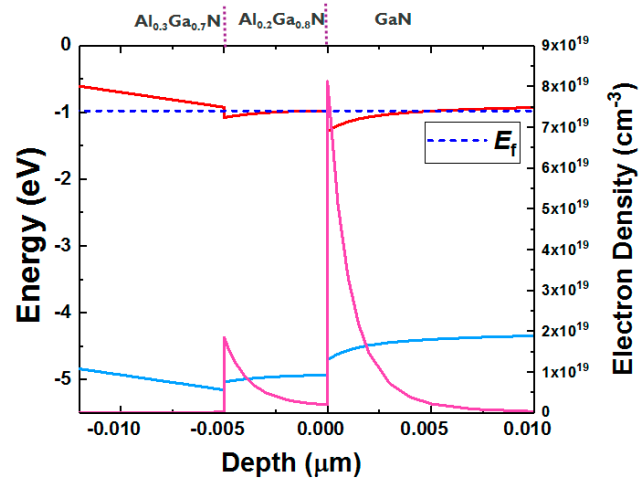

(b)

Figure 3. Simulated band diagrams with an $\mathrm{Al}_{0.3} \mathrm{Ga}_{0.7} \mathrm{~N} / \mathrm{Al}_{0.15} \mathrm{Ga}_{0.85} \mathrm{~N}$ barrier (a) and an $\mathrm{Al}_{0.3} \mathrm{Ga}_{0.7} \mathrm{~N} /$ $\mathrm{Al}_{0.2} \mathrm{Ga}_{0.8} \mathrm{~N}$ barrier (b).

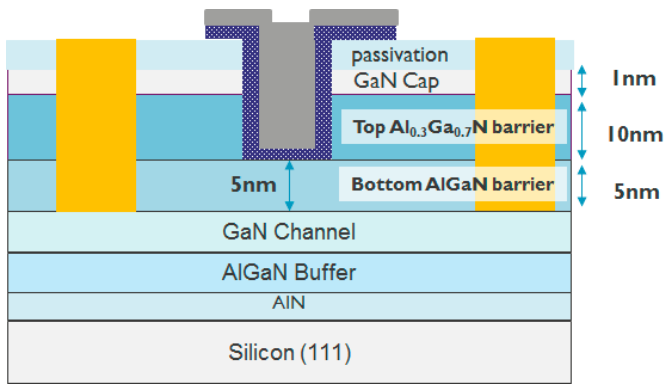

(a)

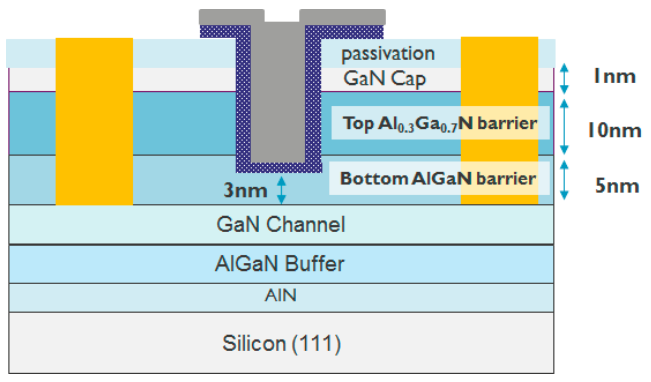

(b)

Figure 4. Schematic of device structures of recessed gate AlGaN/GaN MIS-HEMTs with a $5 \mathrm{~nm}$ remaining bottom AlGaN barrier under the gate region (a) and a $3 \mathrm{~nm}$ remaining bottom $\mathrm{AlGaN}$ barrier under the gate region (b). 
Table 1. Summary of the Varied Parameters.

\begin{tabular}{ccc}
\hline Parameters & Top AlGaN Barrier & Bottom AlGaN Barrier \\
\hline Thickness & $10 \mathrm{~nm}$ & $5 \mathrm{~nm}$ \\
\hline $\mathrm{Al} \%$ & $30 \%$ & $20 \%$ \\
& & $15 \%$ \\
\hline Recessed depth & - & $5 \mathrm{~nm}$ \\
\hline Remaining bottom AlGaN barrier under the gate region & & $3 \mathrm{~nm}$ \\
\hline
\end{tabular}

\section{Results}

In the case of devices with a $5 \mathrm{~nm}$ remaining bottom $\mathrm{AlGaN}$ barrier under the gate area, a gate recess process is performed to etch until it reaches the surface of the bottom AlGaN barrier (Figure 4a). The $I_{\mathrm{D}}-V_{\mathrm{G}}, I_{\mathrm{G}}-V_{\mathrm{G}}$, and $g_{\mathrm{m}}-V_{\mathrm{G}}$ characteristics are shown in Figure 5 . Note that all $I_{\mathrm{D}}-V_{\mathrm{G}}$ characteristics in this work are measured from a lower $V_{\mathrm{G}}$ till a higher $V_{\mathrm{G}}$. A double hump of $g_{\mathrm{m}}-V_{\mathrm{G}}$ characteristic is observed in Figure $5 c$, which is similar to the literature [15-18]. The double hump of $g_{\mathrm{m}}-V_{\mathrm{G}}$ characteristics in these references [15-18] arises from a shrinking of the depletion region below the gate, due to the depletion-mode characteristics. In our case, the recessed gate AlGaN/GaN MIS-HEMTs has a double barrier design. A double channel model that considers the electron transfer from the bottom channel to the top channel is proposed to explain the double hump $g_{\mathrm{m}}-V_{\mathrm{G}}$ characteristics. First of all, once the $V_{\mathrm{G}}$ is larger than $V_{\mathrm{TH}}$, the bottom channel is gradually turned on (Figures 6a and $7 \mathrm{a}$ ), resulting in a first $\mathrm{g}_{\mathrm{m}}$ peak as shown in Figure 5c. It is worth noting that at this stage the top channel from source to drain is initially disconnected below the gate dielectric due to a recessed gate process. However, when the $V_{\mathrm{G}}$ is above $5 \mathrm{~V}$, the top channel could be connected again, as shown in Figure $6 \mathrm{~b}$. In this scenario, the electrons can be transferred from the lateral 2DEG channel in the access region and/or interface below the bottom AlGaN barrier to the interface between the dielectric and the bottom AlGaN barrier [20,21] (Figure $7 \mathrm{~b}$ ). Then, the electrons can be accumulated under the gate dielectric [20,22]. This leads to the formation of the second channel under the gate, further connecting the source and drain to form the top channel leading to a second $g_{m}$ peak (Figure $5 \mathrm{c}$ ).

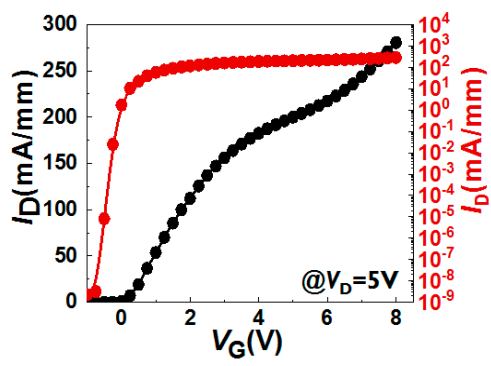

(a)

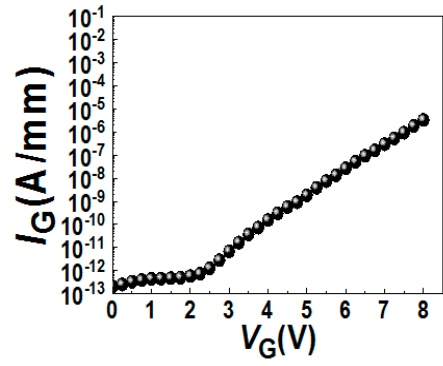

(b)

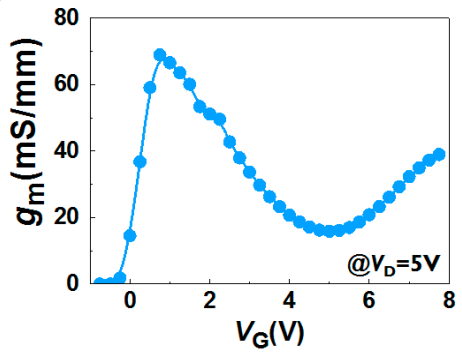

(c)

Figure 5. $I_{\mathrm{D}}-V_{\mathrm{G}}(\mathbf{a}), I_{\mathrm{G}}-V_{\mathrm{G}}(\mathbf{b})$ and $g_{\mathrm{m}}-V_{\mathrm{G}}(\mathbf{c})$ characteristics in a recessed gate MIS-HEMTs with a $5 \mathrm{~nm}$ remaining bottom $\mathrm{Al}_{0.2} \mathrm{Ga}_{0.8} \mathrm{~N}$ barrier under the gate. By designing a $5 \mathrm{~nm}$ bottom $\mathrm{AlGaN}$ barrier with $20 \% \mathrm{Al}$ content, $V_{\mathrm{TH}} \sim 0 \mathrm{~V}$ is realized $\left(V_{\mathrm{TH}}\right.$ is defined at $V_{\mathrm{G}}$ of $I_{\mathrm{D}}=0.1 \mathrm{~mA} / \mathrm{mm}$ ). 

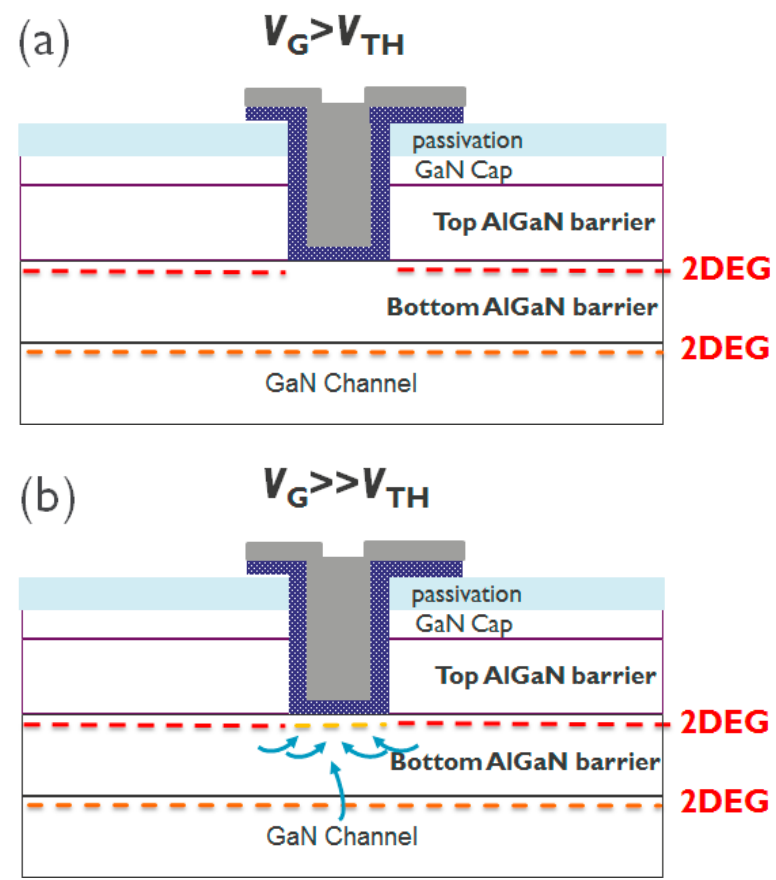

Figure 6. The schematic of proposed double channel model (a) when $V_{\mathrm{G}}>V_{\mathrm{TH}}$ and (b) $V_{\mathrm{G}}>>>V_{\mathrm{TH}}$.
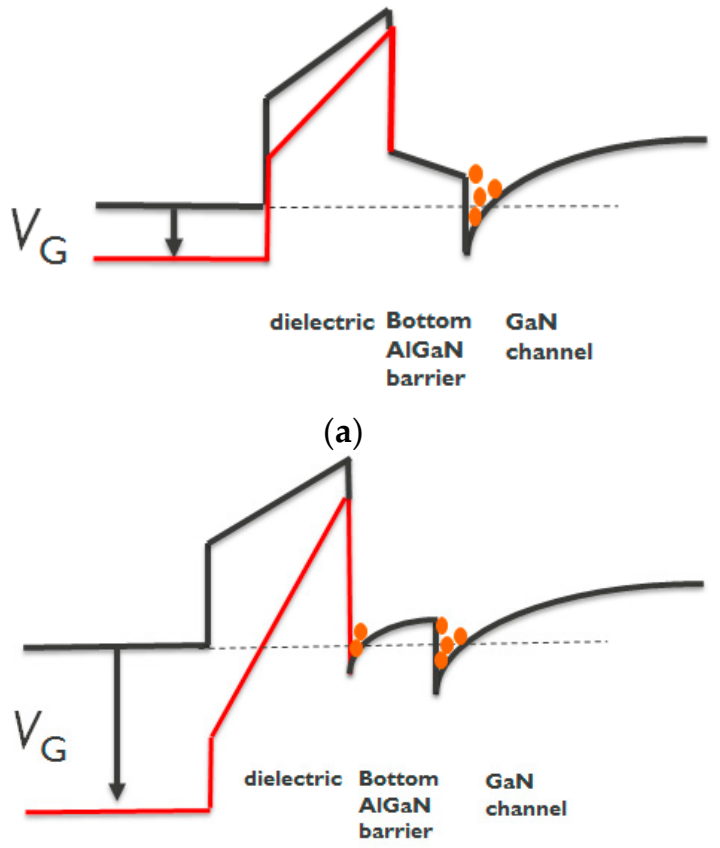

(b)

Figure 7. Schematic of the band diagram under (a) $V_{\mathrm{G}}>V_{\mathrm{TH}}$ and (b) $V_{\mathrm{G}}>>V_{\mathrm{TH}}$.

Figure 8 shows an example of Capacitance-Voltage (CV) measurement in the device with $3 \mathrm{~nm}$ remaining bottom $\mathrm{Al}_{0.15} \mathrm{Ga}_{0.85} \mathrm{~N}$ barrier. The capacitance is increase when the gate voltage is larger than $0 \mathrm{~V}$, indicating the formation of the first channel (Figures 6a and 7a). Once the gate voltage is applied larger enough, the capacitance is increased again, which is mainly due to the formation of the channel between dielectric and bottom AlGaN barrier (Figures $6 \mathrm{~b}$ and $7 \mathrm{~b}$ ), consistent with the reported literature [19]. 


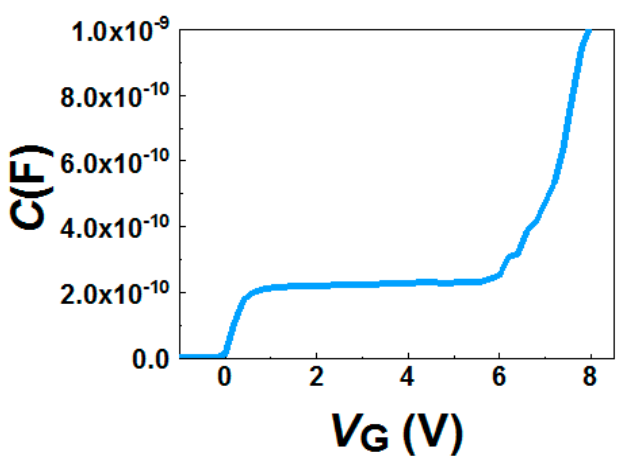

Figure 8. Capacitance-Voltage (CV) measurement in the device with $3 \mathrm{~nm}$ remaining bottom $\mathrm{Al}_{0.15} \mathrm{Ga}_{0.85} \mathrm{~N}$ barrier.

Figure 9 shows the $I_{\mathrm{D}}-V_{\mathrm{G}}$ characteristics in the devices with different $\mathrm{Al} \%$ content $\left(\mathrm{Al}_{0.2} \mathrm{Ga}_{0.8} \mathrm{~N}\right.$ and $\left.\mathrm{Al}_{0.15} \mathrm{Ga}_{0.85} \mathrm{~N}\right)$ in the bottom barriers and two different recessed depths $(5 \mathrm{~nm}$ and $3 \mathrm{~nm}$ bottom AlGaN thickness under the gate area). The $I_{\mathrm{D}}$ decreases but the $V_{\mathrm{TH}}$ increases with a thinner remaining bottom AlGaN barrier (Figure 9b). Furthermore, the subthreshold slope (SS) is increased once the $\mathrm{Al} \%$ in the bottom $\mathrm{AlGaN}$ barrier is decreased, which is mainly due to the low electron density in the channel between bottom $\mathrm{AlGaN} / \mathrm{GaN}$. By designing with $3 \mathrm{~nm}$ remaining bottom $\mathrm{Al}_{0.15} \mathrm{Ga}_{0.85} \mathrm{~N}$ barrier under the gate region, $V_{\mathrm{TH}} \sim 3.25 \mathrm{~V}$ is achieved ( $V_{\mathrm{TH}}$ is defined at $V_{\mathrm{G}}$ of $I_{\mathrm{D}}=0.1 \mathrm{~mA} / \mathrm{mm}$ ).

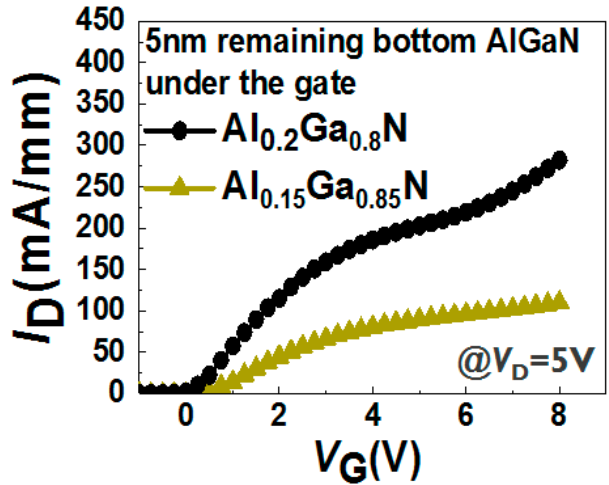

(a)

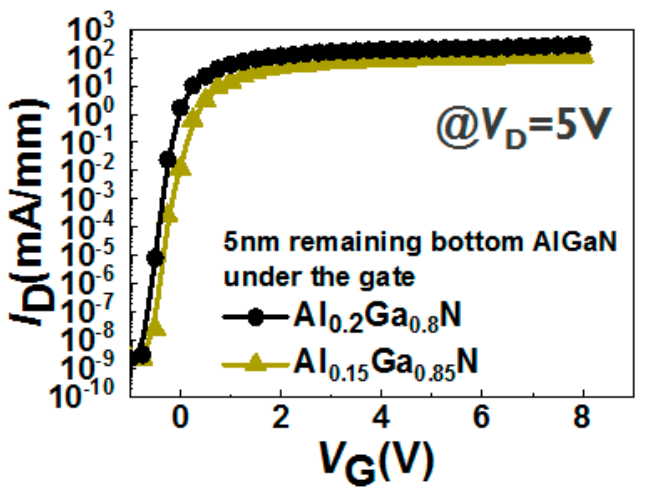

(c)

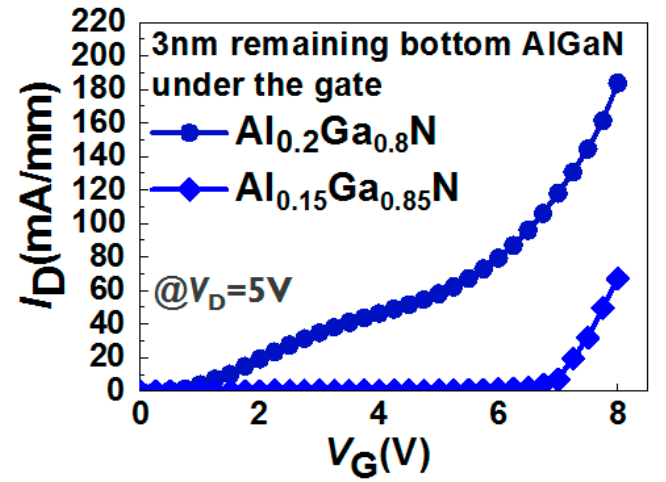

(b)

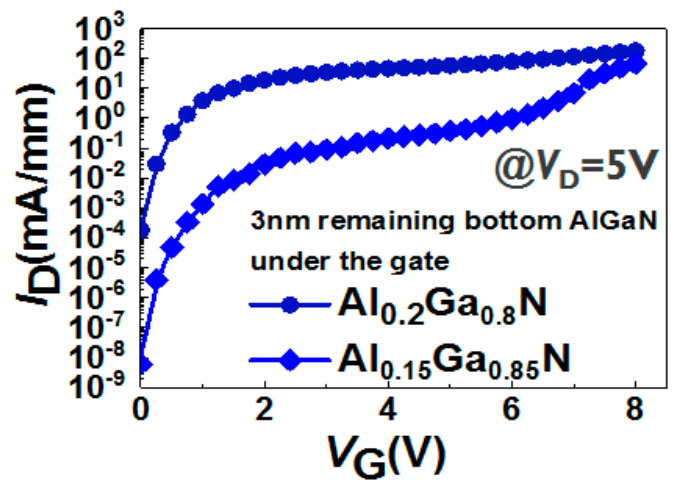

(d)

Figure 9. $I_{\mathrm{D}}-V_{\mathrm{G}}$ in a linear scale $(\mathbf{a}, \mathbf{b})$ and a logarithmic scale $(\mathbf{c}, \mathbf{d})$ in the devices with $5 \mathrm{~nm}$ or $3 \mathrm{~nm}$ remaining bottom $\mathrm{AlGaN}$ layer under the gate region with different $\mathrm{Al} \%$ in the bottom $\mathrm{AlGaN}$ barrier.

Figure 10 shows the $g_{\mathrm{m}}-V_{\mathrm{G}}$ characteristics in the devices with different $\mathrm{Al} \%$ content $\left(\mathrm{Al}_{0.2} \mathrm{Ga}_{0.8} \mathrm{~N}\right.$ and $\left.\mathrm{Al}_{0.15} \mathrm{Ga}_{0.85} \mathrm{~N}\right)$ in the bottom barriers and two different recessed depths $(5 \mathrm{~nm}$ and $3 \mathrm{~nm}$ bottom $\mathrm{AlGaN}$ thickness under the gate area). In the case of the devices with a $5 \mathrm{~nm}$ remaining bottom $\mathrm{AlGaN}$ barrier, lowering the $\mathrm{Al} \%$ in the bottom $\mathrm{AlGaN}$ barrier decreases the $g_{\mathrm{m}}$ peaks (Figure 10a). 
Furthermore, double hump $g_{\mathrm{m}}-V_{\mathrm{G}}$ characteristics can still be observed in the device with a $3 \mathrm{~nm}$ remaining bottom $\mathrm{Al}_{0.2} \mathrm{Ga}_{0.8} \mathrm{~N}$ barrier under the gate region. First, the first $g_{\mathrm{m}}$ peak decreases with a thinner remaining bottom $\mathrm{AlGaN}$ barrier under the gate dielectric, suggesting that the remaining bottom AlGaN barrier under the gate region limits the current contribution from the bottom channel. Second, the $g_{\mathrm{m}}$ increases after $4 \mathrm{~V}$ in the device with a $3 \mathrm{~nm}$ remaining bottom $\mathrm{Al}_{0.2} \mathrm{Ga}_{0.8} \mathrm{~N}$ barrier under the gate region (Figure 10b). Whereas, the $g_{\mathrm{m}}$ increases after $5 \mathrm{~V}$ in the devices with a $5 \mathrm{~nm}$ remaining bottom $\mathrm{Al}_{0.2} \mathrm{Ga}_{0.8} \mathrm{~N}$ barrier under the gate region (Figure 10a). This is in agreement with the model proposed above: Due to a thinner AlGaN barrier, a lower gate voltage can allow the electrons to transfer from the bottom channel to the area below the gate. Third, the second $g_{\mathrm{m}}$ is higher than the first $g_{\mathrm{m}}$ in the devices with a $3 \mathrm{~nm}$ remaining bottom AlGaN barrier under the gate region (Figure 10b). However, the first $g_{\mathrm{m}}$ is higher than the second $g_{\mathrm{m}}$ in the devices with a $5 \mathrm{~nm}$ remaining bottom $\mathrm{AlGaN}$ barrier under the gate region (Figure 10a). These observations suggest that the main current contribution in the devices with a $5 \mathrm{~nm}$ remaining bottom AlGaN barrier under the gate region is the bottom channel. However, in the devices with a $3 \mathrm{~nm}$ remaining bottom AlGaN barrier under the gate region, the main current contribution is derived from the top channel.

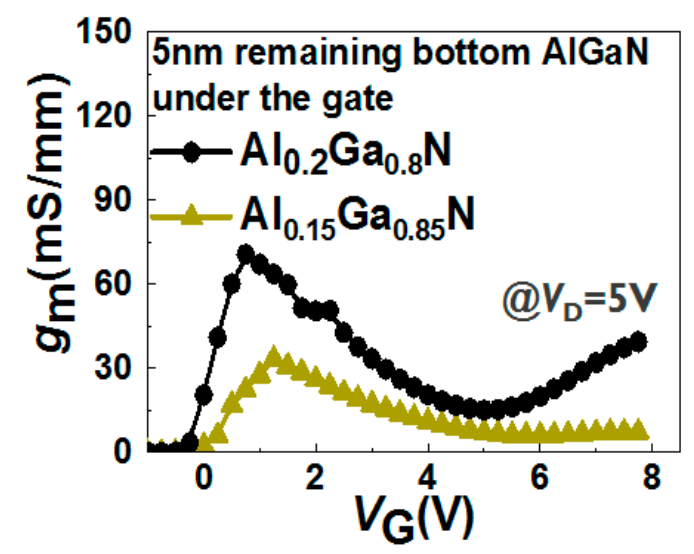

(a)

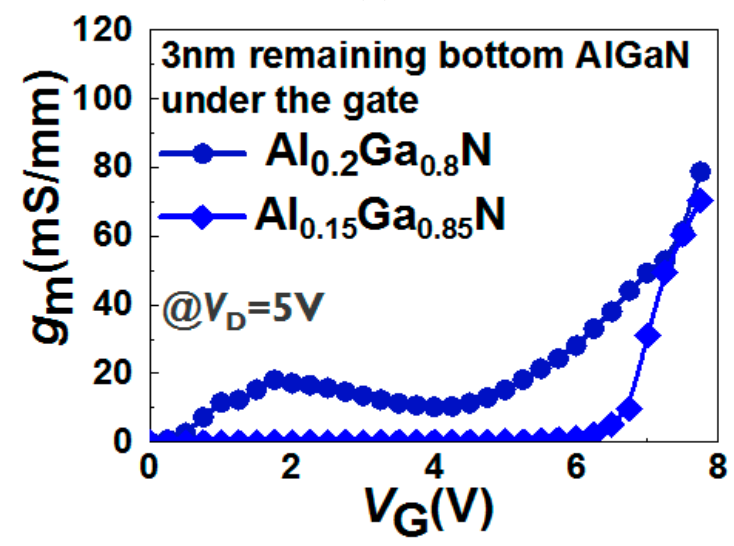

(b)

Figure 10. $g_{\mathrm{m}}-V_{\mathrm{G}}$ characteristics in the devices with a (a) $5 \mathrm{~nm}$ or (b) $3 \mathrm{~nm}$ remaining bottom AlGaN layer under the gate region with different $\mathrm{Al} \%$ in the bottom $\mathrm{AlGaN}$ barrier.

Table 2 summarizes the comparisons of this work with other recent reports in double channel HEMTs, indicating our work shows the promising characteristics in terms of Ion/Ioff ratio and $V_{\mathrm{TH}}$ toward an enhancement mode characteristic. 
Table 2. Reference for the double channel GaN HEMTs.

\begin{tabular}{|c|c|c|c|c|c|c|}
\hline Reference & Barrier designs & $I_{\mathrm{on}} / I_{\mathrm{off}}$ & $\begin{array}{c}\mathrm{SS} \\
(\mathrm{mV} / \mathrm{dec})\end{array}$ & $\begin{array}{c}V_{\mathrm{TH}}(\mathrm{V}) \\
@ 0.1 \mathrm{~mA} / \mathrm{mm}\end{array}$ & $\begin{array}{c}1^{\mathrm{nd}} g_{\mathrm{m}} \\
(\mathrm{mS} / \mathrm{mm})\end{array}$ & $\begin{array}{l}2^{\text {nd }} g_{\mathrm{m}} \\
(\mathrm{mS} / \mathrm{mm})\end{array}$ \\
\hline \multirow{4}{*}{ Our work } & $\begin{array}{c}\mathrm{Al}_{0.3} \mathrm{Ga}_{0.7} \mathrm{~N} / \mathrm{Al}_{0.2} \mathrm{Ga}_{0.8} \mathrm{~N} / \mathrm{GaN} \\
\text { 5nm remaining bottom } \mathrm{Al}_{0.2} \mathrm{Ga}_{0.8} \mathrm{~N}\end{array}$ & $1.2 \times 10^{11}$ & 80.7 & $\sim 0$ & 68.9 & 39 \\
\hline & $\begin{array}{c}\mathrm{Al}_{0.3} \mathrm{Ga}_{0.7} \mathrm{~N} / \mathrm{Al}_{0.15} \mathrm{Ga}_{0.85} \mathrm{~N} / \mathrm{GaN} \\
5 \mathrm{~nm} \text { remaining bottom } \\
\mathrm{Al}_{0.15} \mathrm{Ga}_{0.85} \mathrm{~N}\end{array}$ & $4.8 \times 10^{10}$ & 87.9 & 0.25 & 34.8 & 7.6 \\
\hline & $\begin{array}{c}\mathrm{Al}_{0.3} \mathrm{Ga}_{0.7} \mathrm{~N} / \mathrm{Al}_{0.2} \mathrm{Ga}_{0.8} \mathrm{~N} / \mathrm{GaN} \\
\text { 3nm remaining bottom } \mathrm{Al}_{0.2} \mathrm{Ga}_{0.8} \mathrm{~N}\end{array}$ & - & 153.1 & 0.5 & 18.8 & 90 \\
\hline & $\begin{array}{c}\mathrm{Al}_{0.3} \mathrm{Ga}_{0.7} \mathrm{~N} / \mathrm{Al}_{0.15} \mathrm{Ga}_{0.85} \mathrm{~N} / \mathrm{GaN} \\
\text { 3nm remaining bottom } \\
\mathrm{Al}_{0.15} \mathrm{Ga}_{0.85} \mathrm{~N}\end{array}$ & $5.5 \times 10^{10}$ & 229.3 & 3.25 & - & 71.2 \\
\hline Kamath et al. [17] & $\mathrm{Al}_{0.3} \mathrm{Ga}_{0.7} \mathrm{~N} / \mathrm{GaN} / \mathrm{Al}_{0.15} \mathrm{Ga}_{0.75} \mathrm{~N} / \mathrm{GaN}$ & - & - & $\sim-7.8$ & 34 & 89 \\
\hline Wei et al. [19] & $\begin{array}{c}\text { AlGaN/AlN/GaN/AlN with } 1.5 \mathrm{~nm} \\
\text { over-etch upper GaN layer }\end{array}$ & $\sim 10^{9}$ & 72 & 0.5 & 170 & 103 \\
\hline Lee et al. [23] & $\begin{array}{l}\mathrm{AlGaN} / \mathrm{GaN} / \mathrm{AlGaN} / \mathrm{GaN} \\
\text { Fin Structure }\end{array}$ & - & - & 0.2 & 133 & - \\
\hline Deen et al. [24] & AlN/GaN/AlN/GaN & - & - & $\sim-4$ & 190 & - \\
\hline
\end{tabular}

\section{Conclusions}

In summary, recessed gate AlGaN/GaN MIS-HEMTs with double AlGaN barrier designs are investigated and discussed. A double hump of the $g_{\mathrm{m}}-V_{\mathrm{G}}$ characteristic can be observed in the recessed gate AlGaN/GaN MIS-HEMTs with double AlGaN barrier designs. A physical model is proposed to explain the double channel characteristics, which is mainly due to the formation of the top channel under a high $V_{\mathrm{G}}$ bias. Once the gate voltage is applied at a high enough level, the top channel is formed, leading to an increase in drain current due to the current contribution from the top channel. Furthermore, by lowering the $\mathrm{Al} \%$ in the bottom $\mathrm{AlGaN}$ barrier, the devices show a more positive $V_{\mathrm{TH}}$ with the same recessed depth, indicating that a double AlGaN barrier design in recessed gate MIS-HEMTs can be an alternative strategy to achieve an enhancement mode characteristic.

Author Contributions: Data curation, T.-L.W., S.-W.T., and H.-J.J.; writing-original draft preparation, T.-L.W.; writing-review and editing, T.-L.W., S.-W.T., and H.-J.J. All authors have read and agreed to the published version of the manuscript.

Funding: This work was financially supported by the "Center for the Semiconductor Technology Research" from the Featured Areas Research Center Program within the framework of the Higher Education Sprout Project by the Ministry of Education (MOE) in Taiwan. It is also supported in part by the Ministry of Science and Technology, Taiwan, under Grant MOST-108-3017-F-009-003, MOST-106-2218-E-009-025-MY3 and by the Young Scholar Fellowship Program under Grant MOST 108-2636-E-009-006.

Conflicts of Interest: The authors declare no conflict of interest.

\section{References}

1. Amano, H.; Baines, Y.; Beam, E.; Borga, M.; Bouchet, T.; Chalker, P.R.; Charles, M.; Chen, K.J.; Chowdhury, N.; Chu, R.; et al. The $2018 \mathrm{GaN}$ power electronics roadmap. J. Phys. D Appl. Phys. 2018, 51, 1-48. [CrossRef]

2. Chen, K.J.; Häberlen, O.; Lidow, A.; Tsai, C.L.; Ueda, T.; Uemoto, Y.; Wu, Y. GaN-on-Si power technology: Devices and applications. IEEE Trans. Electron Devices 2017, 64, 779-795. [CrossRef]

3. Van Hove, M.; Boulay, S.; Bahl, S.R.; Stoffels, S.; Kang, X.; Wellekens, D.; Geens, K.; Delabie, A.; Decoutere, S. CMOS Process-Compatible High-Power Low-Leakage AlGaN/GaN MISHEMT on Silicon. IEEE Electron Device Lett. 2012, 33, 667-669. [CrossRef]

4. Moens, P.; Liu, C.; Banerjee, A.; Vanmeerbeek, P.; Coppens, P.; Ziad, H.; Constant, A.; Li, Z.; de Vleeschouwer, H.; RoigGuitart, J.; et al. An Industrial Process for 650 V Rated GaN-on-Si Power Devices Using in-Situ SiN as a Gate Dielectric. In Proceedings of the International Symposium on Power Semiconductor Devices and ICs (ISPSD), Waikoloa, HI, USA, 15-19 June 2014; pp. 374-377. [CrossRef] 
5. Hua, M.; Zhang, Z.; Wei, J.; Lei, J.; Tang, G.; Fu, K.; Cai, Y.; Zhang, B.; Chen, K.J. Integration of LPCVD-SiNx Gate Dielectric with Recessed-Gate E-Mode GaN MIS-FETs: Toward High Performance, High Stability and Long TDDB Lifetime. In Proceedings of the IEEE International Electron Devices Meeting (IEDM), San Francisco, CA, USA, 3-7 December 2016; pp. 10.4.1-10.4.4. [CrossRef]

6. Wu, T.-L.; Marcon, D.; de Jaeger, B.; van Hove, M.; Bakeroot, B.; Lin, D.; Stoffels, S.; Kang, X.; Roelofs, R.; Groeseneken, G.; et al. The Impact of the Gate Dielectric Quality in Developing Au-Free D-Mode and E-Mode Recessed Gate AlGaN/GaN Transistors on a $200 \mathrm{~mm}$ Si Substrate. In Proceedings of the International Symposium on Power Smicond Devices and ICs (ISPSD), Hong Kong, China, 10-14 May 2015; pp. 225-228. [CrossRef]

7. De Jaeger, B.; van Hove, M.; Wellekens, D.; Kang, X.; Liang, H.; Mannaert, G.; Geens, K.; Decoutere, S. Au-Free CMOS-Compatible AlGaN/GaN HEMT Processing on $200 \mathrm{~mm}$ Si Substrates. In Proceedings of the 2012 24th International Symposium on Power Semiconductor Devices and ICs, Bruges, Belgium, 3-7 June 2012; pp. 49-52. [CrossRef]

8. Wu, T.-L.; Marcon, D.; You, S.; Posthuma, N.; Bakeroot, B.; Stoffels, S.; van Hove, M.; Groeseneken, G.; Decoutere, S. Forward bias gate breakdown mechanism in enhancement-mode p-GaN gate AlGaN/GaN high-electron mobility transistors. IEEE Electron Device Lett. 2015, 36, 1001-1003. [CrossRef]

9. Cai, Y.; Zhou, Y.; Chen, K.J.; Lau, K.M. High-performance enhancement-mode AlGaN/GaN HEMTs using fluoride-based plasma treatment. IEEE Electron Device Lett. 2005, 26, 435-437. [CrossRef]

10. Huang, W.; Khan, T.; Chow, T.P. Enhancement-mode n-channel GaN MOSFETs on p and n-GaN/sapphire substrates. IEEE Electron Device Lett. 2006, 27, 796-798. [CrossRef]

11. Lu, B.; Saadat, O.I.; Palacios, T. High-performance integrated dual-gate AlGaN/GaN enhancement-mode transistor. IEEE Electron Device Lett. 2010, 31, 990-992. [CrossRef]

12. Wang, R.; Wu, Y.; Chen, K.J. Gain improvement of enhancement-mode AlGaN/GaN high-electron-mobility transistors using dual-gate architecture. Jpn. J. Appl. Phys. 2013, 47, 2820. [CrossRef]

13. Sheng, N.H.; Lee, C.P.; Chen, R.T.; Miller, D.L.; Lee, S.J. Multiple-Channel GaAs/AlGaAs High Electron Mobility Transistors. IEEE Electron Device Lett. 1985, 6, 307-310. [CrossRef]

14. Gaska, R.; Shur, M.S.; Fjeldly, T.A.; Bykhovski, A.D. Two-channel AlGaN/GaN heterostructure field effect transistor for high power applications. J. Appl. Phys. 1999, 85, 3009-3011. [CrossRef]

15. Chu, R.; Zhou, Y.; Liu, J.; Wang, D.; Chen, K.J.; Lau, K.M. AlGaN-GaN Double-Channel HEMTs. IEEE Trans. Electron Devices 2005, 52, 438-446. [CrossRef]

16. Palacios, T.; Chini, A.; Buttari, D.; Heikman, S.; Chakraborty, A.; Keller, S.; DenBaars, S.P.; Mishra, U.K. Use of Double-Channel Heterostructures to Improve the Access Resistance and Linearity in GaN-Based HEMTs. IEEE Trans. Electron Devices 2006, 53, 562-565. [CrossRef]

17. Kamath, A.; Patil, T.; Adari, R.; Bhattacharya, I.; Ganguly, S.; Aldhaheri, R.W.; Hussain, M.A.; Saha, D. Double-Channel AlGaN/GaN High Electron Mobility Transistor with Back Barriers. IEEE Electron Device Lett. 2012, 33. [CrossRef]

18. Xue, J.; Zhang, J.; Zhang, K.; Zhao, Y.; Zhang, L.; Ma, X.; Li, X.; Meng, F.; Hao, Y. Fabrication and characterization of InAlN/GaN-based double-channel high electron mobility transistors for electronic applications. J. Appl. Phys. 2012, 111, 114513. [CrossRef]

19. Wei, J.; Liu, S.; Li, B.; Tang, X.; Lu, Y.; Liu, C.; Hua, M.; Zhang, Z.; Tang, G.; Chen, K.J. Enhancement-Mode GaN Double-Channel MOS-HEMT with Low On-Resistance and Robust Gate Recess. In Proceedings of the IEEE International Electron Devices Meeting (IEDM), Washington, DC, USA, 7-9 December 2015; pp. 9.4.1-9.4.4. [CrossRef]

20. Mizue, C.; Hori, Y.; Miczek, M.; Hashizume, T. Capacitance-Voltage Characteristics of $\mathrm{Al}_{2} \mathrm{O}_{3} / \mathrm{AlGaN} / \mathrm{GaN}$ Structures and State Density Distribution at $\mathrm{Al}_{2} \mathrm{O}_{3} / \mathrm{AlGaN}$ Interface. Jpn. J. Appl. Phys. 2011, 50, 021001. [CrossRef]

21. Wu, T.-L.; Marcon, D.; Ronchi, N.; Bakeroot, B.; You, S.; Stoffels, S.; van Hove, M.; Bisi, D.; Meneghini, M.; Groeseneken, G.; et al. Analysis of Slow De-trapping Phenomena after a Positive Gate Bias on AlGaN/GaN MIS-HEMTs with in-situ $\mathrm{Si}_{3} \mathrm{~N}_{4} / \mathrm{Al}_{2} \mathrm{O}_{3}$ Bilayer Gate Dielectrics. Solid-State Electron. 2015, 103, 127-130. [CrossRef] 
22. Lagger, P.; Steinschifter, P.; Reiner, M.; Denifl, G.; Naumann, A.; Wilde, L.; Sundqvist, J.; Pogany, D.; Ostermaier, C. Role of the dielectric for the charging dynamics of the dielectric/barrier interface in AlGaN/GaN based metal-insulator-semiconductor structures under forward gate bias stress. Appl. Phys. Lett. 2014, 105, 033512. [CrossRef]

23. Lee, J.-H.; Kim, J.-G.; Ju, J.-M.; Ahn, W.-H.; Kang, S.-H.; Lee, J.-H. AlInGaN/GaN double-channel FinFET with high on-current and negligible current collapse. Solid-State Electron. 2020, 164, 107678. [CrossRef]

24. Deen, D.A.; Miller, R.A.; Osinsky, A.V.; Downey, B.P.; Storm, D.F.; Meyer, D.J.; Katzer, D.S.; Nepal, N. Polarization-mediated Debye-screening of surface potential fluctuations in dual-channel AlN/GaN high electron mobility transistors. Appl. Phys. Lett. 2016, 120, 235704. [CrossRef]

C 2020 by the authors. Licensee MDPI, Basel, Switzerland. This article is an open access article distributed under the terms and conditions of the Creative Commons Attribution (CC BY) license (http://creativecommons.org/licenses/by/4.0/). 